\title{
Monetary Policy Transmission Mechanism in Nigeria: A FAVAR Approach
}

\author{
Frances Ngozi Obafemi ${ }^{1} \&$ Eugene Okoi Ifere ${ }^{1}$ \\ ${ }^{1}$ Department of Economics University of Calabar, Calabar, Nigeria \\ Correspondence: Eugene Okoi Ifere, Department of Economics University of Calabar, Calabar-Nigeria. Tel: \\ 234-805-405-7717. E-mail: eugeoifere@yahoo.com
}

Received: May 27, 2015

Accepted: June 18, 2015

Online Published: July 25, 2015

doi:10.5539/ijef.v7n8p229

URL: http://dx.doi.org/10.5539/ijef.v7n8p229

\begin{abstract}
Empirical evidence on the effectiveness, dominant and the exact channel through which monetary policy impact the Nigerian economy is at best mixed. Against this backdrop, this paper set out to investigate this mixed evidence by exploring a data-rich environment using a FAVAR model estimated with 53 variables spanning the quarterly period of 1970:01 to 2013:04. Overall, the results showed that interest rates and credit channels are the dominant and strongest channel of transmission of monetary shocks in Nigeria, followed by Exchange rate and money channel. Stock channel, has no significant impact in the transmission process. Based on these result, we recommended that the Central Bank of Nigeria should improve on the use of the interest rate and credit channels as monetary policy variables through a policy approach of stimulating and emphasizing judicious management. This has the capacity to stimulate growth in distinct sectors of the economy.
\end{abstract}

Keywords: monetary policy, transmission mechanism, FAVAR

\section{Introduction}

One of the most unsettled monetary policy issues in Nigeria and other emerging market economies is the identification of the most effective monetary transmission mechanism. Although there exists other contemporary challenging monetary policy issues calling for attention such as the problem of lag (impact), price stability, environment in which monetary policy is operating, effectiveness of standard monetary policy measures in steering inflation, "secular stagnation" meaning a persistent state of economic depression (Praet, 2014). Despite the measures taken by Central Bank of Nigeria (CBN) and monetary policy makers in recent times, the economy has failed to respond favorably and the transmission mechanism of monetary policy has continued to be uncertain

For any economy to go the right direction on the path of growth the monetary policy transmission mechanism as a pathway through which monetary policy choices influence the general economy should be identified. However, on the contrary, evidence on the strength, effectiveness and dominant channels of the transmission mechanism of monetary policy in Nigeria are at best mixed and very few Studies like (Jimoh, 1990; Oke, 1995; Uchendu, 1994; Ojo, 2000; Nnnana, 2001; Adebiyi, 2006; Ajayi, 2007; CBN, 2007, 2008, 2010; Adebiyi \& Mordi, 2009; Mbutor, 2009; Oyaromade, 2011; Nwosa \& Saibu, 2012) have had mixed results on the effective, dominance and exact channels of monetary policy transmission in Nigeria . These studies employed different methodologies ranging from qualitative findings, use of single equation macro models, reduced-form Vector Autoregressive (VAR) models or at most Vector Error Correction Models (VECMs), which, in turn, limits their variables to at most 4 to 8 in order to conserve the degrees of freedom. Despite adoption of different monetary policy regimes, empirical studies have shown poor performance of the Nigeria economy. The poor performance of the economy further suggests that the lofty objectives of monetary policy may have been negatively affected by the inadequate knowledge of the exact channel through which monetary signals transmit to the economy.

In spite of its advantage, Factor-augmented Vector Autoregressive (FAVAR) methodology as an alternative method of identifying channels of monetary transmission has not been used by any study in Nigeria. Interestingly most studies, which adopt the Factor Augmented Auto-regressive (FAVAR) methodology are concentrated on the US economy and other industrialized nations. These studies include Deleeviw and Gramlich (1969), Sealey (1979), Bernanke and Blinder (1988), King (1986), Sim (1992), Bernanke and Gertler (1995), Taylor (1995), Bernanke, Boivin, and Eliasz (2005), Mishkin (2007), Boivin, Kiley, and Mishkin (2010) among 
others. However, the use of Factor Augmented Vector Auto-regression (FAVAR) methodology of Bernanke et al. (2005) is still lacking in Nigeria despite its advantage of using large information data.

Against this backdrop, this paper is an attempt at identifying the impact, strength, effectiveness and dominant channel of monetary policy transmission in Nigeria by exploring the FAVAR methodology using 53 quarterly series over the period 1970:01 to 2013:04. Given its econometric construct, the FAVAR model might solve some of the problems associated with other methods. To the best of our knowledge, this is the first attempt to analyze the impact of monetary policy transmission channels in Nigeria using wide information set that accounts for the various sectors of the economy. The remainder of the paper is organized as follows: Section 2 briefly discusses monetary policy in Nigeria while, Section 3 discusses the conceptual framework, FAVAR model, identification structure and choice of factors. Section 4 reports and analyzes the impulse response function of factors used for the study following a monetary policy shock, and Section 5 concludes.

\section{Monetary Policy in Nigeria}

Monetary transmission channels vary across countries due to certain factors which may include; macroeconomic environment and structural economic conditions, the extent of development of capital markets, the health of and extent of development within the financial system as well as the major monetary policy instruments used by the country. According to Sanusi (2009), "an efficient and effective transmission mechanism of monetary policy can only be assured in an economically safe and sound environment characterized by a competitive banking system".

Monetary Policy has existed in Nigeria from the early years of the Central Bank (1959) and the structure for conducting monetary policy has witnessed a number of transformations. During this time direct approaches to monetary management were the main technique of monetary policy implementation with a latter shift to indirect (market-based) approach in 1993. The direct approach (1974-1992) placed emphasis on direct monetary control. During this period, the CBN conducted Monetary Policy by relying on credit ceilings as well as sectoral credit allocation. Monetary Policy during this era was directed by the Ministry of Finance and persuaded by short term political factors. The structure and level of interest rates was determined administratively by the CBN. Both lending and deposit rates were fixed with the aim of actualizing by fiat, the social best-case scenario in the allocation of resource, and to promote growth of the financial market. According to Nnanna(2001), during this period of direct control of Monetary Policy, monetary authorities directed financial resources at a compromise rate to sectors considered with right of precedence.

Indirect Monetary Policy (Market-based) approach started in 1993 with a shift from the repressive monetary control. This approach was adopted with the intent of eliminating all the twist and ineffectiveness in the financial system, triggered by the persistent usage of administrative controls with the objective of stimulating competition within the financial system (Ibeabuchi, 2007). The major indirect monetary instrument from 1993 is the Open Market Operation (OMO). This was later complimented by the reserve requirement, CBN securities and Moral suasion. The OMO involves the purchase or sale of eligible bills or securities by CBN in the open market with the aim of influencing deposit money bank's reserve balances, base money as well as the financial state of affair (Nnanna, 2007). However, despite the different monetary policy measures and transformational frameworks taken by $\mathrm{CBN}$ in recent times, the economy has failed to respond favorably and the exact channel of transmission mechanism of monetary policy has continued to be uncertain and unidentified, hence the need to explore the FAVAR approach.

\section{Conceptual FAVAR Framework}

The Factor Augmented VAR (FAVAR) is structurally built on dynamic factor model. This model was first formulated by Bernanke, Boivin and Eliaz (2005). They augmented a standard VAR model with factors and it was used for identifying the shocks of monetary policy on macroeconomic variables. The FAVAR model solves a major weakness of the traditional (VAR) which utilizes limited volume of information. The other beauty of the FAVAR framework is in the ability to permit the measurement of the influence of monetary policy using large macroeconomic variables (Senbet, 2008).

The matrix structure of FAVAR methodology involves two methods of estimation. This procedure involves a two-step technique using principal component analysis (Senbet, 2008). It involves extracting or estimating the factors using principal component analysis. The second step is incorporating the estimated factors into a VAR model as inputs along with monetary policy measure. Factors are employed in the FAVAR models instead of the real variables. Each of these factors is orthogonal and therefore does not expect the cointegration among factors.

According to (Senbet, 2008), the key procedures in estimating the FAVAR techniques starts with "conducting principal component analysis using all the large informational time series data set (variables) represented by 
(Nx1) vector of $\mathrm{V}_{t}$ to get the first $\mathrm{K}+\mathrm{M}$ principal components denoted by $\mathrm{C}\left(\mathrm{F}_{t} \mathrm{Y}_{t}\right)$ " These estimated factors $\mathrm{F}_{t}$ are included in the space covered by $\mathrm{C}\left(\mathrm{F}_{t} \mathrm{Y}_{t}\right)$ which is not covered by $\mathrm{Y}_{t}$, after which the dependence of $\mathrm{C}\left(\mathrm{F}_{t} \mathrm{Y}_{t}\right)$ on $\mathrm{y}_{t}$ is removed by first, dividing the series in $\mathrm{Xt}$ into fast and slow- moving variables. Variables assumed to be simultaneously reactive to policies are said to be the fast moving variables (Senbet, 2008). They are extremely responsive to simultaneous policy shocks or news such as financial assets and stock market prices (Bernanke et al., 2005). On the other hand, the slow moving variables do not simultaneously respond to monetary policy. They are not simultaneously responsive to policy shocks. After this procedure, is the use of Principal Component Analysis (PCA) to obtain matrix of slow moving factors $\mathrm{C}\left(\mathrm{F}_{\mathrm{t}}\right)$ and the regression.

$$
C\left(F_{t} Y_{t}\right)=B^{f} C\left(F_{t}\right)=B^{y} Y_{t}+e_{t}
$$

After the estimated factors are obtained, then the VAR models that include $\mathrm{f}_{\mathrm{t}}$ and $\mathrm{Y}_{\mathrm{t}}$ is estimated. In this case the $\mathrm{Y}_{\mathrm{t}}$ covers the monetary policy instruments while rest of the variables such as inflation and output were handled as unobservable variables (Bernanke et al., 2005).

However, in using this method of principal components, its application may be either on the original $\mathrm{x}_{\mathrm{j}}$ 's or on their deviations from the means (xj's) or on the standardized values of the original variables $\left(\mathrm{z}_{\mathrm{j}}=\mathrm{x}_{\mathrm{j}} / \mathrm{s}_{\mathrm{xj}}\right)$. In this case, the values of the principal components are often different. Therefore, this dependence on the unit of measurement is characterized as one of the serious weakness of the principal component technique (Theil, 1971).

\subsection{The FAVAR Model}

The FAVAR method assumes that pertinent theoretical concept of interest are known and completely observed. It rather regards observable variables as "noisy indicators of the true but unobservable state of the economy". Adopting FAVAR framework using large information from large number of macroeconomic indicators is one sure way of addressing the limitations of other methods. Adopting Senbet (2008), therefore;

Let $\mathrm{X}_{\mathrm{t}}$ be an $(\mathrm{N} \times 1)$ vector of informational time series stationary variables.

Let $\mathrm{Y}_{\mathrm{t}} \mathrm{be}$ an $(\mathrm{M} \mathrm{x} 1)$ vector of observable stationary time series economic variables assumed to affect the changes in the economy. $Y_{t}$ is a subset of $X_{t}$, and this may include policy variables and other observable measures of prices and real activity. Often times, estimation using the VAR framework use only these observable measures summarized by about four to eight variables. One of the identified limitations of this approach is that $Y_{t}$ cannot incorporate the same information set as $\mathrm{X}_{\mathrm{t}}$.

According to Bernanke et al. (2005), assume a hand full of the information in Xt can be effectually abridged by a handful of unobserved $(\mathrm{K} \times 1)$ vectors of factors, Ft. "it is common place to think of the unobserved factors as capturing fluctuations in unobserved potential output or reflecting theoretically motivated concepts such as economic activity, price pressures, that cannot easily be represented by one or two series but rather reflected in a wide range of economic variables". According to Favero et al. (2005), the idea underlying the factor models is that "the economy is driven by a few common forces or factors and idiosyncratic errors". Studies by Stock and Watson (2005), and Favero et al. (2005), showed that"the vibrant factor model expresses Yt as a distributed lag of a small number of unobserved factors and idiosyncratic disturbances that are accepted to be serially correlated".

$$
\begin{array}{r}
Y_{t}=\lambda(L) F_{t}+u_{t} \\
U_{t}=\delta(L) u_{t-1}+v_{t}
\end{array}
$$

Where

Ft is a $(\mathrm{K} \times 1)$ vector of unobserved dynamic factors,

$\lambda(L)$ is an $(\mathrm{M} \times \mathrm{K})$ dynamic factor loadings and vtis said to be the white noise. Assume that the factors and disturbances are not correlated

Therefore equation (2),

$$
\begin{gathered}
U_{t}=[I-\delta(L) L]^{-1} v_{t}, \text { and hence }(1) \text { becomes } \\
Y_{t}=\Lambda(L) F_{t}+\delta(L) Y_{t-1}+V_{t}
\end{gathered}
$$

Where

$$
\begin{gathered}
\Lambda(L)=[I-\delta(L) L] \lambda(L) \text { Define the evolution of factors as } \\
F_{t}=\Phi(L) F_{t}+\eta_{t}
\end{gathered}
$$

Where 
$\eta_{\mathrm{t}} \mathrm{is}$ a $(\mathrm{K} \times 1)$ disturbance vector.

Substituting (4) into (3) and rearranging

$$
Y_{t}=\Lambda(L) \Phi(L) F_{t-1}+\delta(L) Y_{t-1}+\omega
$$

Where $\omega_{t}=\Lambda(L) \eta_{t}+v_{t}$.

Combining equation (5) with the factor evolution equation (4) yields the FAVAR model:

$$
\left(\begin{array}{c}
\mathbf{F}_{\mathbf{t}} \\
\mathbf{Y}_{\mathbf{t}}
\end{array}\right)=\left(\begin{array}{c}
\Phi(\mathrm{L}) \\
\Lambda(\mathrm{L}) \Phi(\mathrm{L}) \\
\delta(\mathrm{L})
\end{array}\right)\left(\begin{array}{ll}
\mathrm{F}_{\mathrm{t}-1} \\
\delta & \mathrm{Y}_{\mathrm{t}-1}+
\end{array}\right)\left(\begin{array}{ll}
\eta_{\mathrm{t}} & \\
& \omega_{\mathrm{t}}
\end{array}\right)
$$

Assuming the terms in $\Phi(\mathrm{L})$ is all zero then; the above system is reduced to the traditional VAR. If the true system is FAVAR, then the major defect of standard VAR framework is in the omitted variable bias. Furthermore, the above expression for FAVAR nests the VAR model (i.e., when $\Phi(\mathrm{L})=0$ ), this makes the two models easy to compare.

\subsection{Choice of Factors}

In order to get clear interpretation of factors for the FAVAR analysis, we borrow the novel ideas of Belviso and Milani (2006) who partitioned the vector of economic variables $X_{t}$ to give them a clear meaning. For the purpose of this study, the factors chosen for determining the effectiveness of monetary transmission in Nigeria based on the factor loadings and correlation in each principal component are as follows:

Financial market factor: The financial market factor is introduced to test for efficiency and effectiveness of stock prices, asset prices and dividend indexes in the channel of monetary policy transmission. It has been observed that financial market shocks have an impact on real output either positively or negatively. So the inclusion of this factor will enable us to have a proper insight into the working of financial markets in monetary policy transmission. Since financial market responds immediately to policy, there is need to model it.

Money factor: This factor is important because it explains a number of money stock variables in the Nigerian economy that can have influence on monetary policy. They include M1, M2, currency in circulation, Reserve money, private sector demand, Deposits of Money Bank at the CBN and Total Value of Money Market Instruments.

Inflation factor: This denotes in a nutshell, a wider perception of inflation in Nigeria. Variety of data in this area such as producer and consumer prices, food inflation, fuel and energy inflation and all other prices such as oil prices may be incorporated as series in this factor.

Credit factor: As important as this factor may seem to be, it is usually disregarded in standard VARs. With this factor, we will be able to verify the first hand significance of credit channel of monetary transmission. The variables for the factor will include available series of private credit and loan variables.

Interest rate factor: Interest rate factor captures public and private bonds yield at different maturities, and the influence of monetary policy rate on the other interest rate in the economy.

Exchange rate factor: The choice of exchange rate factor is because it is an intermediate policy variable of monetary policy transmission. This link can be through its impact on the domestic inflation (the pass-through effect), value of domestic currency, the external sector, capital flows, and financial stability.

Real activity factors: This factor which provides a summary of the state of real output in Nigerian economy was not included in the final naming of factors because the variables did not load highly in the principal component. The Variables include capacity utilizations, industrial production, consumer expenditures and other macroeconomic variables. Generally, "the real activity factor can be re-conducted to the theoretical macroeconomic concept of output gap" (Belviso \& Milani, 2006).

\section{Empirical Results}

In order to know exactly the proportional contributions and importance of policy variables to variations in given macroeconomic variables as well as the direction of these movements, we use the impulse response and variance decomposition. Impulse response and variance decompositions give a clearer and true picture of transmission mechanism in an economy. This is important in finding out if monetary policy actions affect macro variables or output negatively or positively. The variance decomposition seeks to measure the comparative importance of 
every random innovations or shocks. It decomposes the forecasting error variance of any particular variable at different time horizons by its source. It helps to indicate which variables have short and long-term impacts on another variable of interest. In this way, the percentages of the fluctuations in a time series attributable to other variables are made clear.The results of the estimated impulse responses and variance decomposition of macroeconomic variables to an unanticipated monetary policy shake up in Nigeria is presented thus.

\subsection{Impulse Response Function of Monetary Aggregates}

The impulse response of aggregate macroeconomic money variables (Figure 1) reflects its own gradual decrease showing a falling pattern in the first three quarters. After the fourth quarter it levels out completely within the benchmark zero line. The impulse response functions of monetary aggregates to interest rates, credit, exchange rate, inflation and stock market rates reveals a sharp and small negative fall from the zero baselines up to the third quarter before picking up gradually to terminate at the zero line. In terms of forecast error variance error decomposition, the result showed that the variation in monetary aggregate accounted for by its own shock seems to be the highest and varies from 100 percent within the first quarter to 97.29 percent over 10 period horizons.

Response to Cholsesky One S.D. Innovations \pm 2 S.E.
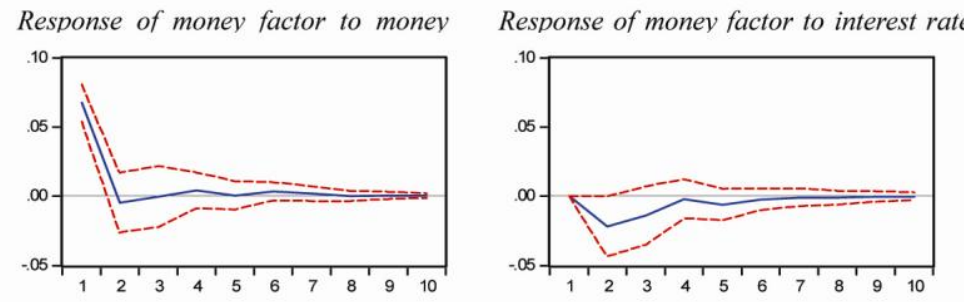

Response of money factor to credit
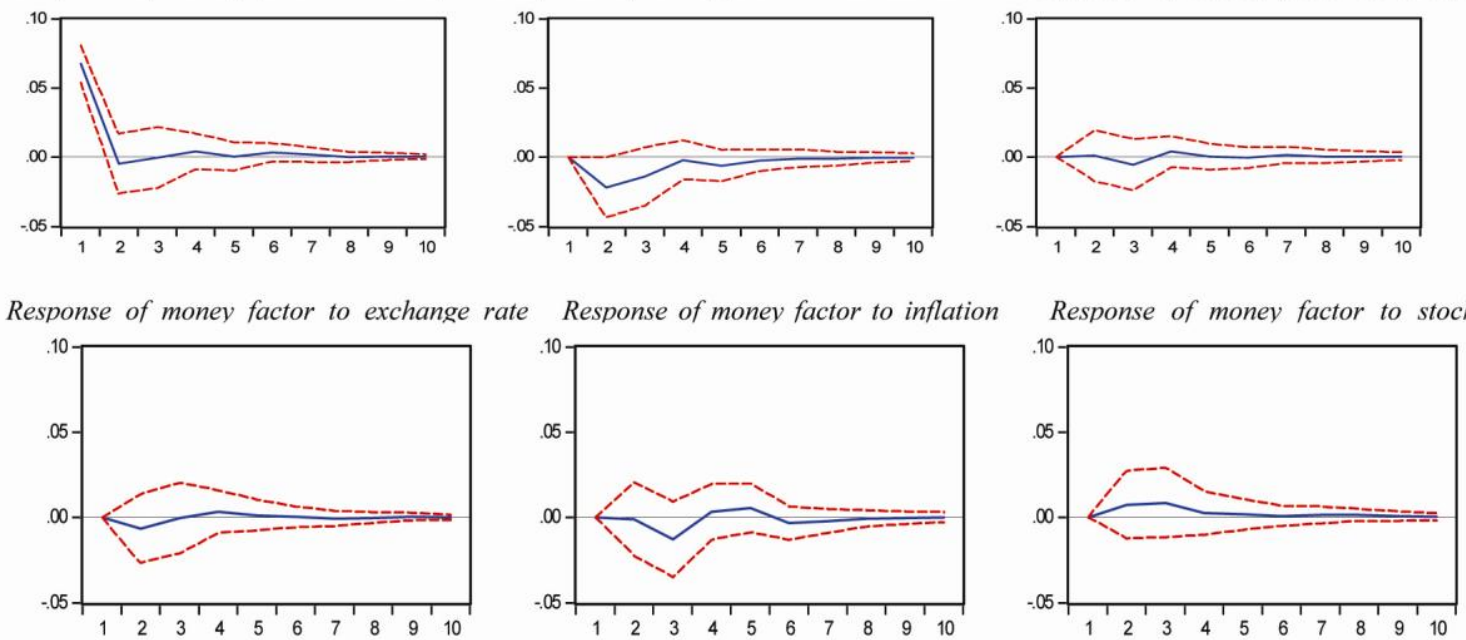

Figure 1. IRF of monetary aggregates

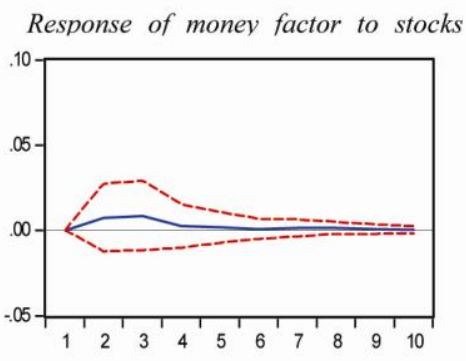

\subsection{Impulse Response Function of Interest Rate Channel}

For the interest rate channel (Figure 2), minimum rediscount rate (MRR) serves as the monetary policy shock variable. The impulse response function of interest rate to monetary aggregates reveals that an unanticipated contractionary monetary policy results in an initial weak positive and then a gentle fall in monetary aggregates reaching a minimum in the third quarter and began to respond sluggishly after the fourth quarters leveling out at zero. This is consistent with Ndekwu (2013) who asserts that interest rate seems to have had weak impact on the real economy during the period 1981 to 2008. The impulse response of interest rates can be said to be consistent with a priori expectation. Interest rate replicates positive shock of its own and drops uninterruptedly from above the first five quarters. This shows a gentle falling pattern stagnating at the baseline i.e. zero benchmark by the seventh quarter. The observed gentle fall can be credited to the stifling consequence of contractionary monetary policy on the economy. The estimated impulse response of interest rates to credit shows an initial rise (albeit with weak statistical significance) before leveling out at the benchmark after the third quarter. This shows that short term interest rate affect credit through some other factors such as exchange rate and stock market factors. This reveals that a rise in interest rate first attracts credit and slowly dampens it.

Monetary policy shock on exchange rate responds negatively to interest rates within the first two quarters before taking levels over the short to medium term. This shows that exchange rate shock reacts negatively to monetary tightening in the short term before taking levels. Apriori, monetary tightening i.e. a rise in local interest rate will make deposits denominated in local currency to be further appealing and this result in local goods being more costly than foreign goods. This causes a drop in export after deductions and total output. The impulse response 
function of interest rate to inflation reveals a gyration of sharp negative fall up to the second quarter and a rise in the fourth quarter before leveling out to the benchmark level. This is in agreement with economic theory that interest rate affects inflation in the short run. "A given interest rate will produce much more monetary restraint when inflation is low and less volatile than when inflation is high". The gyration may be associated with lags in transmission channels "which are due to the time it takes for aggregate demand to respond to changes in interest rates and the time it takes for inflation to respond to output gaps" (Ajayi, 2007).

Following monetary policy tightening, stocks responds slowly and negatively to interest rate and reaches the benchmark in the sixth quarter. A priori, stocks become more attractive to buy in a low interest rate regime by raising households' financial assets.

Forecast error variance decomposition of interest rate on money aggregates showed that the variation in interest rate accounted for by monetary aggregates is low and varies from 4.8per cent in the first quarter thereafter leveling out at 8.3 per cent from the third quarter to 8.7 per cent over the ten period horizons. However, the percent forecast error variance of interest rate on its own shock seems to be the largest among the six transmission channels of monetary policy under discussion.

Response to Cholsesky One S.D. Innovations \pm 2 S.E.

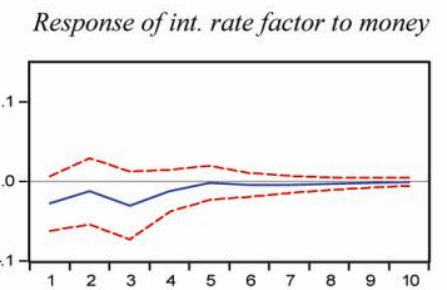

Response of int. rate factor to Exch rate

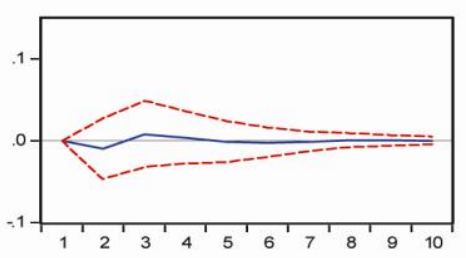

Response of int. rate factor to int rate

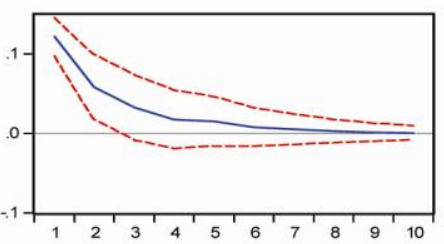

Response of int. rate factor to inflation

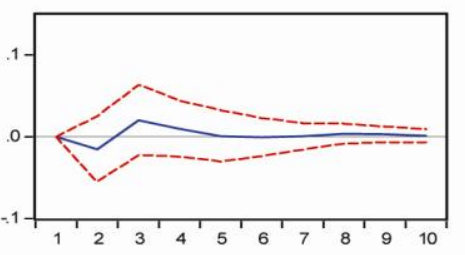

Response of int. rate factor to credit

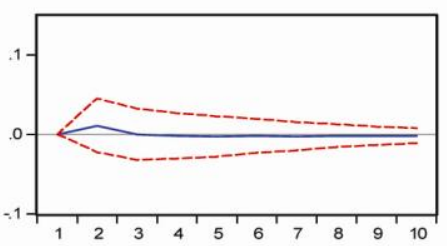

Response of int. rate factor to Stock

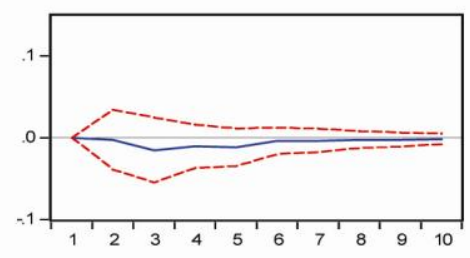

Figure 2. IRF of interest rate channel

\subsection{Impulse Response Function of Credit Channel}

The impulse response function of credit to monetary aggregates (Figure 3) shows that a one standard deviation shock to monetary aggregates results in a sharp increase in credit from below the zero benchmark levels reaching a peak after the fourth quarter and then leveling out. Also, a contractionary monetary policy reveals that a one standard deviation shock to interest rate results in a sharp fall in credit at levels in the medium and long term. In other words, a monetary policy shock on credit channel reflects its own positive shock falling sharply from above the first quarter before rising from the second quarter and then start descending from the fourth quarter after which it finally levels out at the sixth quarter.

For exchange rate and inflation, the impulse response functions of credit showed a negative decline from the benchmark zero level in the fourth quarters and then leveling out in the sixth quarter. This shows that credit affect inflation and exchange rate in the economy negatively. This result is in line with results obtained by Ndekwu (2013) that credit channel in the financial sector provides a linchpin in the process by which monetary policy impact the economy in Nigeria between 1981 to 2008.

As regards credit factor, the forecast error variance decomposition result shows that variations in credit factor accounted for by its own shock is the highest and varies from 84.79 percent in the first quarter to 54 percent from the fourth quarter up to the tenth quarter. The variations of credit in response to other monetary policy transmission channels are very low. That for money factor varies from 15 to 12 percent from the first to the tenth quarter. 
Response to Cholsesky One S.D. Innovations \pm 2 S.E.

Response of Credit factor to money

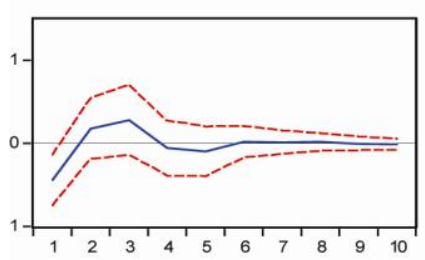

Response of Credit factor to exch rate

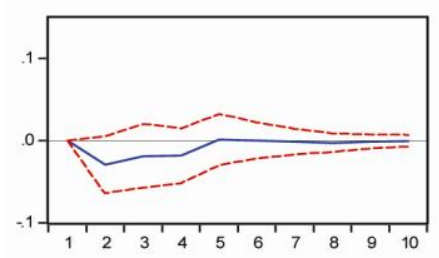

Response of Credit factor to int. rate

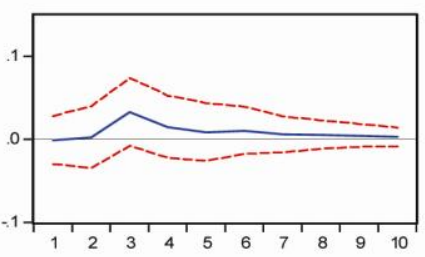

Response of Credit factor to inflation

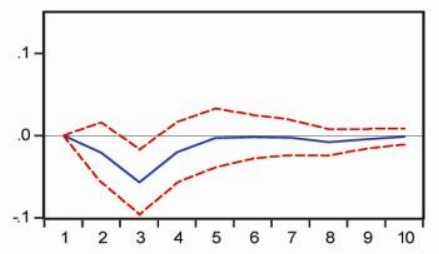

Response of Credit factor to credit

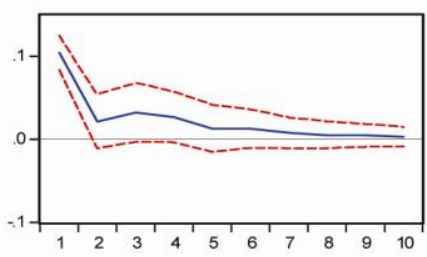

Response of Credit factor to stock

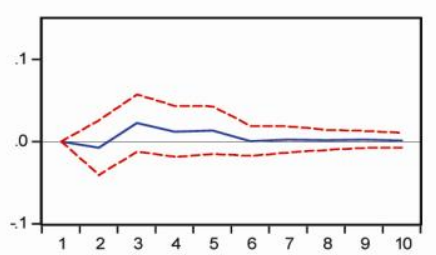

Figure 3. IRF of credit channel

\subsection{Impulse Response Function of Exchange Rate Channel}

Real effective Exchange Rate (REER) served as the monetary policy shock variable for Exchange Rate channel in each period. In the exchange rate factor (Figure 4), a one standard deviation shock to monetary aggregate results in a sharp and steady increase in exchange rate peaking at the fourth quarter then makes a sharp return up to the fifth quarter before leveling out in the seventh quarter. The impulse response of exchange rate to inflation shows that a one standard deviation shock to interest rate results in a positive but slow movement of exchange rate up to the fifth quarter before descending and leveling in on the zero bench mark.

The variation of exchange rate in response to other transmission channel such as credit, inflation and stock channel factors are very low and they range from eight to 11 percent for credit factor; four to seven percent for inflation factor and one to two percent for the stock factor, respectively

Response to Cholsesky One S.D. Innovations \pm 2 S.E.

Response of exch rate factor to money

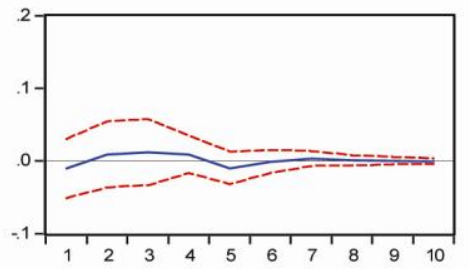

Resnonse of exchrate factor to exch rate

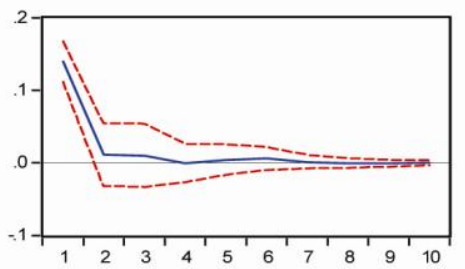

Response of exch rate factor to int rate

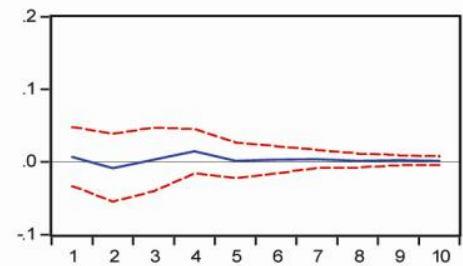

Response of exch rate to inflation

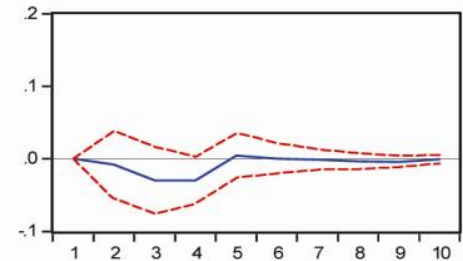

Response of exch rate factor to credit factor

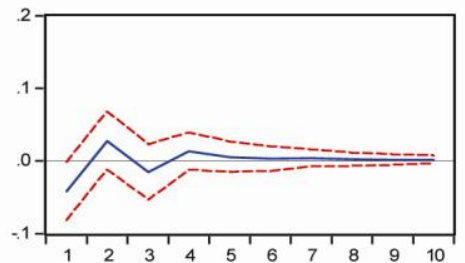

Resnonse of exch rate to stock mkt

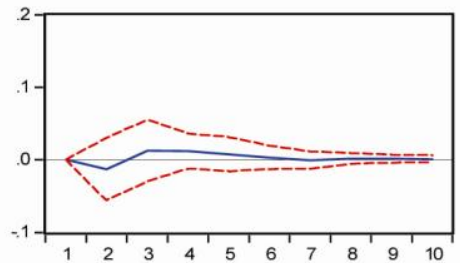

Figure 4. IRF of exchange rate channel

\subsection{Impulse Response Function of Inflation Channel}

In the wake of a monetary policy tightening, the impulse response of inflation to monetary aggregates (Figure 5), 
initially rises slightly above the benchmark level after the second quarter and then gradually declines, leveling out from the third over the medium to the long term. A monetary tightening reveals an impulse response of inflation to interest rate below the zero benchmark level from the first quarter to the tenth quarter. This is in line with economic theory that high inflation and prices influence interest rates or cost of capital in an economy.

The impulse response function of inflation to both credit and exchange rate reported in levels, both falls below the benchmark level from the short to medium term. For credit, there exist a sharp fall and indeed below the zero benchmark level up to the fourth quarter following a tight monetary policy before leveling out. While that of exchange rate leveled out from the first quarter to the tenth quarter. This is an indication that monetary policy tightening affects credit more sharply than exchange rate.

The impulse responses function of inflation shows that an unexpected monetary tightening results in a sharp fall in prices, reaching its maximum level after the fourth quarter and at the benchmark level through the medium term. This is consistent with apriori expectation that a tight monetary policy lowers prices, proxied by inflation.

From the variance decomposition result,the forecast error variance decomposition, of inflation channel on money aggregates (Figure 2-5), showed that the variation in inflation rate accounted for by monetary aggregates is low and levels out from 6.1 to 6.5 per cent from the first to tenth period horizons, respectively.

Response to Cholsesky One S.D. Innovations \pm 2 S.E.

Response of inflation factor to monev

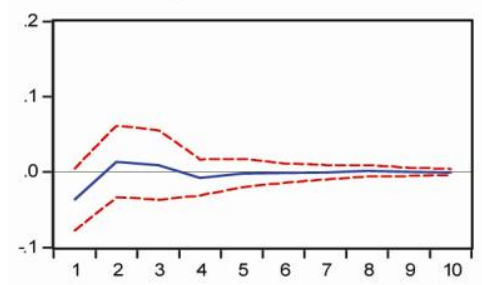

Response of inflation factor to exch rate

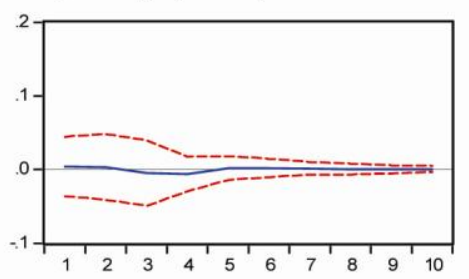

Response of inflation factor to int rate

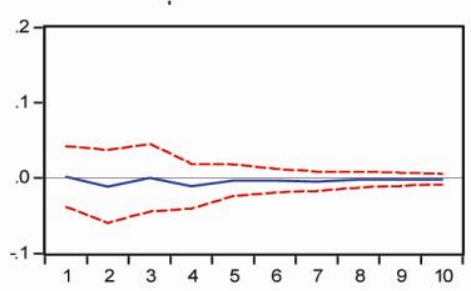

Response of inflation factor to inflation

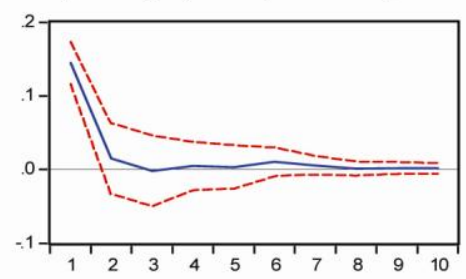

Response of inflation factor to credit

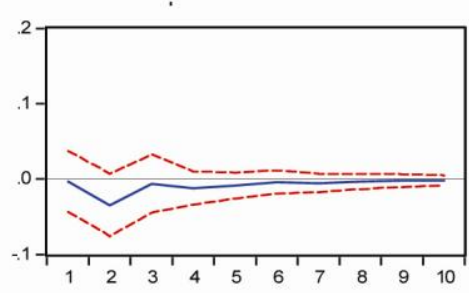

Response of inflation factor to stock

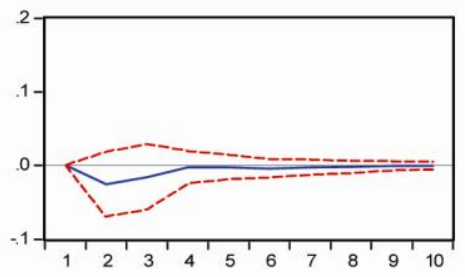

Figure 5. IRF of inflation channel

\subsection{Impulse Response Function of Stock Market Channel}

Figure 6 displays the impulse responses of the relationship between Stocks and interest rate . A monetary policy tightening implemented through monetary aggregates such as credits and exchange rate, results in a slow movement of stocks above levels up to the third quarter and then starts declining up to the sixth quarter before reaching the zero bench mark. For inflation, the trend is swift and sharper, as a one standard deviation shock to inflation generates sharp gyrations in stock prices factor, reaching a peak in the third quarter with a sharp fall up to the fifth quarter before leveling out from below at the sixth quarter.

For stocks, a one standard deviation shock resulting from monetary tightening reflects a sharp and negative shock up to the zero benchmark in the second quarter. The percent forecast error variance of stock market factor due to its own shock seems to be the largest among the six monetary policy transmission channels under discussion. The monetary policy shock on stock factor explains more than half of the variance over the tenth period horizon. This variation ranges from 98.09 percent in the first quarter to 80.68 percent in the tenth period horizon 
Response to Cholsesky One S.D. Innovations \pm 2 S.E.

Response of Stock to money factor

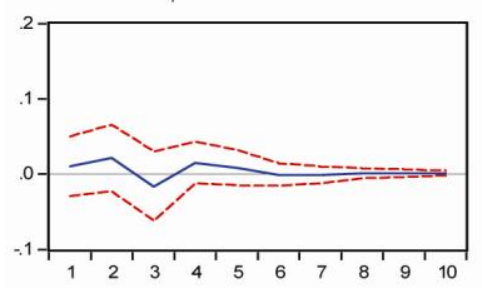

Response of Stock to stock $\mathrm{mkt}$

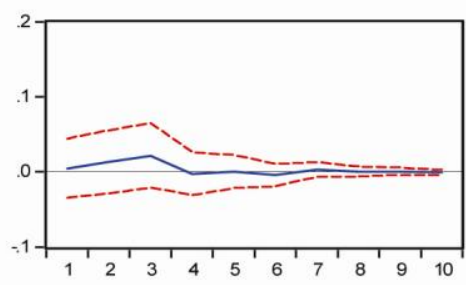

Response of Stock to interest rate

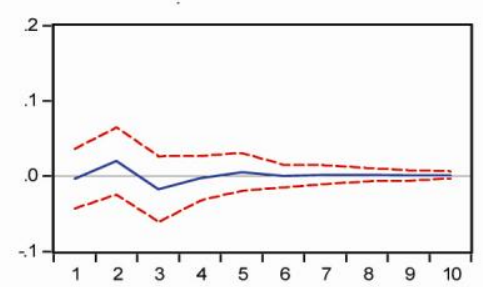

Response of Stock to inflation

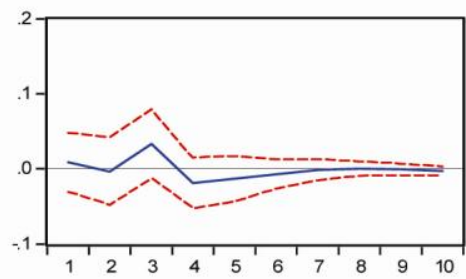

Response of Stock to credit factor

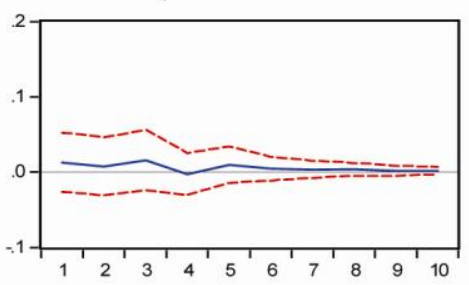

Response of Stock to Stock

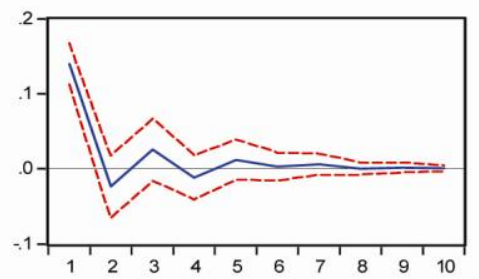

Figure 6. IRF of stock market channel

\section{Conclusion}

The study set out to empirically test the strength and dominant channels of monetary transmission that exists in Nigeria. It employed a FAVAR methodology which enabled the study to take advantage of a large array of macro variables in order to have a better and clearer representation of the transmission mechanism of monetary policy in Nigeria. Quarterly data from 1970 to 2013 was used. In all, 53 observations/data points on the selected macroeconomic variables were used. The estimation of factor was performed using PCA. The impulse responses showed the reactions of macroeconomic variables to shocks in monetary policy for FAVAR models. A clear knowledge of the transmission channels of monetary policy performance to the economy is sacrosanct to this study.

In order to test for the strength and dominant monetary transmission channels that exist in the Nigeria economy as contained in our hypothesis, the FAVAR model was estimated and the impulse response and variance decomposition results showed that interest rates and credit channels are the dominant and strongest channels of monetary transmission in Nigeria. Another identified channel is the money channel, although negligible. This shows that M2 has an impact on monetary policy in Nigeria.

Our specific findings indicate that in terms of the strength of channels of transmission, the interest rates and credit channels are the dominant and strongest channel of transmission of monetary shocks in Nigeria as seen in the impulse responses obtained. The exchange rate and money channel were also significant in the transmission process but not as pronounced as the other two channels (interest and credit channels). For example, the decline in money aggregates, stocks, exchange rates and a sharp but small rise in credit is consistent with higher interest rates. A slight increase in exchange rate shocks has small impact on macroeconomic variables. This may be explained by the fact that exchange rate channel does not have a strong influence on transmission of monetary policy in Nigeria. For stock channel, there is no significant impact found. This indicates that the stock market channel plays an insignificant part in the transmission process in Nigeria. When transmission occurs, they are immediate and they level out within the first two quarters.

The FAVAR results on monetary dynamics, which is the core interest of this research concludes that a tight monetary policy shock triggers monetary growth before putting forth a dampening influence on the economy, leveling out at the zero bench mark in the medium to long term. This way, the Central Bank of Nigeria uses the interest rate and credit channels as policy variables to impact the economy. The FAVAR model allows for the generation of impulse functions for several variables in the data set hence providing a comprehensive picture of monetary policy transmission in Nigeria. Findings from the study suggest that the FAVAR model is a superior alternative when dealing with large number of data set.

The fact that interest rate and credit channels were identified in this study as the dominant and effective channels of transmission in Nigeria followed by exchange rate channel, we recommend that the CBN should improve on 
the use of these channels as policy variables in monetary policy conduct. To achieve this, it is recommended that the policy approach of stimulating and emphasizing judicious management of interest rate and credit as well as exchange rate channels of transmission should be pursued. This has the capacity to stimulate growth in distinct sectors of the economy. To stimulate output for development through credit channel of transmission, government and monetary policy makers should strengthen the Nigeria judicial system and improve on financial regulatory reforms. These reforms can come through tightening of credit worthiness standards of potential borrowers. This will cut down the amount of non-performing loans and enhance quality of credit, which in turn will strengthen the credit channel of transmission mechanism. Also more legal backing should be given to the Nigeria Deposit Insurance Corporation(NDIC) and other regulatory agencies of the CBN. This can be achieved through the enforcement of regulations requiring commercial banks to strengthen their accounting standards, corporate governance as well as improve and strengthen creditors' rights and capabilities of banks to assess credit applications and enforce collateral.

\section{References}

Adebiyi, M. A. (2006). Inflation targeting: Can we establish a stable and predictable policy instrument between inflation and monetary policy instrument in Nigeria and Ghana? Retrieved from http://www.google.com.ng

Adebiyi, M. A., \& Mordi, C. N. O. (2009). Monetary policy transmission mechanism in estimated dynamic stochastic general equilibrium (DGSE) for the Nigerian economy. CBN Economic and Financial Review.

Ajayi, M. (2007). Monetary policy transmission mechanism in Nigeria. Central Bank of Nigeria Economic and Financial Review, 45(4), 91-107.

Belviso, F., \& Milani, F. (2006). Structural factor-augmented VARs (SFAVAR) and the effects of monetary policy. Topics in Macroeconomics, 6(3), 1-46.

Bernanke, B. S., \& Blinder, A. S. (1988). Credit money and aggregate demand. American Economic Review Papers and Proceedings, 78, 435-439.

Bernanke, B. S., \& Gertler, M. (1995). Inside the black box: The credit channel of monetary policy transmission. Journal of Economic Perspective, 9(4), 27-48.

Bernanke, B., \& Eliasz, P. (2005). Measuring the effects of monetary policy: A factor-augmented vector autoregressive (FAVAR) approach. The Quarterly Journal of Economics, 120(1), 387-422.

Boivin, J., Kiley, M. T., \& Mishkin, F. (2010). How has the monetary transmission mechanism evolved over time? NBER Working Papers, (15879), National Bureau of Economic Research, Inc.

Central Bank of Nigeria. (2010). Monetary Policy Review. CBN Half Year Economic Report for 2010. Retrieved from http://www.cbn.gov.ng

De Carvalho, M. D., \& Rossi, J. L. (2009). Identification of monetary policy shocks and their effects: FAVAR methodology for the Brazilian economy. Brazilian Review of Econometrics, 29(2), 285-313.

Ibeabuchi, O. (2007). Overview of monetary policy in Nigeria. Central Bank of Nigeria Economic and Financial Review.

Jimoh, A. (1990). The monetary approach to balance of payments: Evidence from Nigeria. Eastern Africa Economic Review, 6(1), 69-75.

Mbutor, M. O. (2009). The dominant channels of monetary policy transmission in Nigeria: An empirical investigation. CBN Economic and Financial Review, 47(1).

Mishkin, F. S. (2007). Housing and monetary transmission mechanism. Staff Working Papers in the Finance and Economic Discussion Series (FEDS) Jackson Hole Symposium, Jackson Hole, Wyoming.

Ndekwu, E. C. (2013). An analysis of the monetary policy transmission mechanism and the real economy in Nigeria. Central Bank of Nigeria occasional papers No. 43.

Nnanna, O. J. (2001). Monetary policy framework in Africa: The Nigerian experience. Discussion paper, South African Reserve Bank Conference.

Nwosa, P. I., \& Saibu, M. O. (2012). The monetary transmission mechanism in Nigeria: A sectoral output analysis. International Journal of Economics and Finance. Retrieved from http://dx.doi.org/10.5539/ijef.v4n1p204

Ojo, M. O. (2000). Principles and practice of of monetary management in Nigeria. CBN Economic and Financial Review. 
Oke, B. A. (1995). The conduct of monetary policy by the central bank of Nigeria (1959-1995). CBN Economic and Financial Review, 33(4).

Oyaromade, R. (2011). Monetary Policy Transmission Mechanism in Nigeria: A VECM Approach. Nigeria Journal of Economic and Social Studies (NES) Journal, 44(2), 231-251.

Praet, P. (2014). Current issues in monetary policy. ECB Discussion paper at the Peterson Institute for International Economics Washington DC $\quad$ Retrieved from http://www.ecb.europa.eu/press/key/date/2014/html/sp141209

Sanusi, L. A. S. (2009). Assessment of Current development in the Nigerian economy and the CBN policy action. BIS Review, 89.

Senbet, D. (2008). Measuring the impact and international transmission of monetary policy: A factor augmented vector autoregressive (FAVAR) approach. European Journal of Economics, Finance and Administrative Studies, (13).

Sims, C. A. (1992). Interpreting the time series facts: The effects of monetary policy and financial repression and economic growth. European Economic Review, 36(5).

Taylor, J. B. (1995). The monetary transmission mechanism: An empirical framework. Journal of Economic Perspectives, 9(4), 11-26.

Theil, H. (1971). Principles of Econometrics (pp. 46-55). John Wiley.

Uchendu, O. A. (1996). The transmission of monetary policy in Nigeria. Economic and Financial Review, Central Bank of Nigeria, 34(2), 606-625.

\section{Copyrights}

Copyright for this article is retained by the author(s), with first publication rights granted to the journal.

This is an open-access article distributed under the terms and conditions of the Creative Commons Attribution license (http://creativecommons.org/licenses/by/3.0/). 